\title{
Crowdsourcing historical photographs: autonomy and control at the Copenhagen City Archives
}

\author{
Karin Hansson* ${ }^{1,2}$ [1] \& Anna Näslund Dahlgren ${ }^{1}$ \\ *l Department of Culture and Aesthetics, Stockholm University, SE-106 91 Stockholm, Sweden \\ (E-mail: khansson@dsv.su.se); ${ }^{2}$ School of Natural Sciences, Technology and Environmental \\ Studies, Södertörn University, Huddinge, Sweden (E-mail: khansson@dsv.su.se)
}

Accepted: 1 November 2021

\begin{abstract}
This study of crowdsourcing practices at Kbhbilleder.dk at the Copenhagen City Archives provides a rich description of how motivation and work relations are situated in a wider infrastructure of different tools and social settings. Approximately, $94 \%$ of the work is here done by 7 of the 2,433 participants. The article contributes insights into how these super-taggers carry out their work, describing and placing images on a map, through an extensive discursive effort that takes place outside the institution's more limited interface in private discussion forums with over 60000 participants. The more exploratory qualitative work that is going on in different discussion groups does not fit within the archive's technical framework. Instead, alternative archives are growing within privately owned networks, where participants' own collections merge with images from public archives. Rather than focusing on the nature of participants' motivation, the article suggests a relational perspective on participation that is useful for analyzing a systems' support for participation. Pointing out how people's motivation in citizen science correspond with relational and intrarelational aspects enables an approach to system design that potentially supports or counteracts these aspects.
\end{abstract}

Keywords: Crowdsourcing, alienation, motivation, metadata, super-taggers, visual heritage, citizen science

\section{Introduction}

The digitization of cultural heritage material demonstrates decisive differences between textual and visual sources. While text can be readily processed and accessed via OCR scan, for example, images still require considerable manual effort as there are few means to automate the metadata. Many attempts are therefore being made to solve this by engaging the general public through citizen science projects, gathering a large crowd of volunteers in the annotating and tagging of images. 
While crowdsourcing projects in the area of citizen science has been the topic for innumerable studies within the sciences and social sciences, there are fewer projects in the humanities (Dobreva 2016). These are foremost in more collaborative areas such as archeology where, for example, crowdsourcing has been successfully used in connection with landscape (Parcak 2017). Projects in the galleries, libraries, archives and museums (GLAM) sector have primarily comprised smaller and easier tasks, such as mass text transcription (De León 2015; Eveleigh et al. 2013). However, crowdsourcing metadata for images are still in the minority in the stocktaking on the digitization of cultural heritage in general and crowdsourcing alike, which can be seen as an indirect effect of the text dominance in crowdsourcing per se (Borowiecki et al., 2016; Cameron and Kenderdine, 2007; Grau, 2017; Ridge, 2014).

Oomen and Aroyo (2011), highlight two critical challenges for crowdsourcing in GLAMs: quality and motivated participants. This corresponds with recent studies on citizen science and digital images in the cultural heritage domain which display two different strands: The first dominant strand, based on experimental design or prototype evaluations, focuses on the efficiency of crowdsourcing, that is, if and how the crowd can replace or complement the expert descriptor. For example, studies have shown that with the right guidance novices can be used as a complement to experts when tagging film clips (Darvish and Chin, 2010; Liliana et al., 2017). A combination of expert and novice annotation types can also provide richer descriptions (Manzo et al. 2015). Its also acknowledged that people in these contexts often are higly competent, pursuing amateur activities to professional standards (Ridge 2013). When it comes to still images, crowdsourcing has proven to be useful for annotating limited aspects of archival photographs, yet more extensive annotating require professional expertise (Oosterman et al. 2015). User-generated tagging practices online also challenge the idea of more controlled metadata vocabularies (Rorissa 2010). However, the risk of affecting long-term sustainability seems to be a major issue in the cultural heritage sector (Manzo et al. 2015). A challenge for user-generated metadata processes has been termed by van Hooland et al. (2011) as the 'commodification of culture' - the notion of placing more value on the present accessibility of materials than on future accessibility ensured by authority control.

The second strand focuses on motivation, that is, if and how the crowd can be motivated to participate. Gamification has been explored specifically as a mean to motivate the crowd to contribute with micro-tasks such as for example geo-tagging of images (Bujari et al., 2017; Seaborn and Fels, 2015). Developing public knowledge and thus strengthening motivation by emphasizing particular themes rather than isolated data collection is also suggested, based on the findings from research on crowdsourcing in archeology (Bevan et al. 2014). 
When it comes to issues regarding control and power relations, between institutions, between institutions and users, and between users, there are less research. But there are potentially interesting questions here, for example:

- The relational dimensions of image archiving, and the relations between formal cultural heritage archives and informal, when, platforms such as Flickr potentially can connect the archives of private users with large institutions (Terras 2011).

- The digital differentiation and relations within the crowd, which become important when crowdsourcing is motivated for democratic reasons in order to engage a larger audience. Studies of crowdsourcing tools such as Amazon Mechanical Turk (Fort et al. 2011), Wikipedia (Menking and Erickson, 2015; Ortega et al., 2008) and Twitter (Duggan et al. 2015), indicate a lack of diversity in terms of age, gender and education. Cultural geographers have also pointed out the hegemonic discourses and sociospatial relations in the geographic web (Crampton et al., 2013; Shelton et al., 2014; Soden and Palen, 2014; Zook et al., 2015). Not surprisingly, Amazon Mechanical Turk (AMT) studies comparing systems offering no monetary rewards with those that do, reveal different demographic groups (Gewald and Pilz, 2013; Kaufmann et al., 2011).

- The effect of datafication on volunteer participation, where new digital labor relations that commodify all online activities might create an extreme form of alienation where human labor is exploited twice: the technology on one hand enables online commons, while on the other hand, the data it produces (e.g. user behavior patterns) is commodified, mined and alienated from the users (Andrejevic 2011; Scholz 2013). Different aspects of this exploitation have been studied in other areas, for example: the working conditions of crowd workers (Irani and Silberman, 2013; Martin et al., 2016), self-exploitation (Webster and Randle, 2016), and the social media surveillance practices (Andrejevic 2011). However, these discussions are about paid labor; the implication this might have for volunteer work needs to be further explored.

Motivating a diverse crowd to participate in these highly surveilled publics is one of the more pressing problems that need to be solved. Here it becomes increasingly interesting to understand the relations between formal and informal archives, while also acknowledging differences and inequalities within these settings. In order to address these questions and the scarcity of studies on the crowdsourcing of images in the humanities in a Scandinavian context, we have looked at a case in Denmark where crowdsourcing was used as a way to enrich images of the city of Copenhagen with metadata. In the following sections, we discuss our theoretical starting point regarding motivating 
participation in crowdsourcing. The case study, where we mix ethnographic methods with an interface analysis focusing on the production relations, gives a broad picture of the infrastructure that enables the crowdsourcing.

\section{Motivating participation a matter of power distribution}

When looking at the research on motivation in citizen science in cultural heritage the focus is typically on the nature of their participation: Strong motivational factors are often recognized in, for example, the need for autonomy and learning, recognition, community and belonging (see e.g., Brewer et al., 2016; Rotman et al., 2012). In unpaid citizen science projects participants are mostly motivated by a keen personal interest in the subject, and learning about science may be another motivation (Jones et al. 2018). A desire to contribute to knowledge is another important outcome for citizen science generally (Reed et al. 2013). For historical projects an interest in the past, a furthering of the participant's own research, contributing to the greater good, personal challenge and pleasure in doing the task, are all major motivations for volunteers (Aucott et al. 2019; Bonacchi et al. 2019). In an overview of the GLAM sector, 'connectedness and membership' and 'sharing and generosity' are seen as the main motivational factors for participation (Oomen and Aroyo 2011). In grassroots archiving such as Flickr, motivation is about identity and belonging (Terras 2011). Studies of paid crowdsourcing such as in ATM show that motivation connected to participants' need for autonomy and learning is important in these contexts as well (Kaufmann et al. 2011).

Although it is of course interesting to identify these motivational factors, you can also describe these factors in terms of power. After all, including public participation in the development of the cultural heritage is about delegating power. To identify the power relations in these contexts, we have therefore turned to Karl Marx's (1844) theory on alienation. This theory describes power in terms of relationships, where connectedness gives the individual great autonomy and control over their work, and weak relationships reduce the individual's ability to understand and control their work, alienating their relations to their work and consumers of this work, but instead it is the system that governs through various incentives such as points or salary.

In Marx's ideal world everyone is linked in mutual relationships with others and nature, connectedness and self-actualization is the driving force, and production is a mutual exchange that strengthens individual identity (Marx 1844). The most important relationship, according to Marx, is the individual's relationship to themselves. This can be compared to intrinsic motivation, because it is about enjoyment, a feeling that one's competence is put to use, and that the values of the individual's own identity are confirmed by knowing that they contribute to a larger context. The second relationship, Marx claims, is related to what one 
does, and that the individual has direct control over their own work. The third is the relationship to other workers, where there is reciprocity and community with others in a similar situation. The fourth relationship is with the consumer of one's work, in that there is a mutual recognition and respect between producer and consumer.

Focusing on the participants' opportunity for these different types of relationships, rather than the nature of their potential motivation, gives us a perspective on participation that is not only useful for analyzing incentives, but can also be valuable when thinking about how different systems support participation. If we assume that people's motivation in citizen science corresponds with their relationship to themselves, to their work, and to other participants and audiences, then we can also more easily design systems that potentially support or counteract these relationships. Here Hansson et al.'s (2018) adaptation of Marx's theory of alienation is useful in seeing how the interfaces support/counteract individuals' relationships to themselves and their interests, to other participants and their communities, to the production and to the product (Figure 1):

- The relationship within the producer, i.e. between the producer and the self: In a context of crowdsourcing, is the participant an object who provides data without control, or an active subject with autonomy and competence?

- The relationship between the producers and their product: What is the underlying ontology? Is the work described as 'bits and pieces', an active contribution, a dialogue, or an expression by a subject with their own agenda?

Figure 1. A typology of alienation and relationship in crowdsourcing (See detailed typology descriptions in the Appendix).

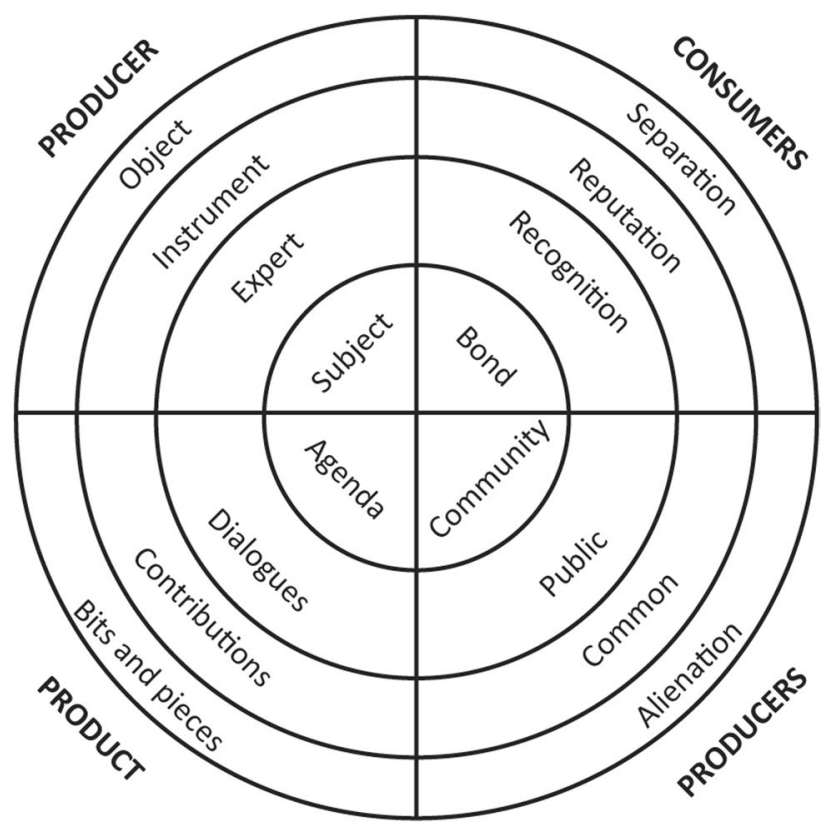


- The relationship between the producers and the consumer of the work: Is there a separation in the platform between the participant producing the data and the participant using the data, or do they have the means to recognize each other?

- The relationship between producers: What is the available tool support for peer-to-peer communication? Does the interface express a particular group awareness? Can participants communicate shared interests or establish a community, or are they alienated from each other?

With these questions in mind, this study seeks to understand the factors that constitute the production relations when tagging images in a crowdsourcing tool, especially regarding differences and tensions within and between formal and informal archives.

\section{Data and method}

In her overview of citizen science projects in the humanities Dobreva (2016) calls for a better understanding of the specific features of collective knowledge production in the humanities. Therefore, in order to understand the conditions for participatory archiving processes, the broader infrastructure must be the primary focus, rather than a single interface or institution.

Many studies of crowdsourcing are about a single institution and/or the use of an interface. Here, we seek to give a broader picture and scrutinize what other contexts than the crowdsourcing tool the super-taggers are situated in and the conditions for crowdsourcing in relation to these other contexts. Rather than studying a single interface and a single institution, we try to understand the design as the sum of the relational conditions the individual has to manage, what in design contexts can be called the infrastructuring, describing the socio-technical setting that supports, for example, a public (Björgvinsson et al., 2012; Dantec and DiSalvo, 2013). The concept of infrastructuring describes a more holistic relationship to the design process, and design that is not about designing things but enabling processes, where infrastructure indicates the entire network of human and non-human actors, including cultural norms and behaviors (Karasti et al. 2018).

Ideally, the infrastructure arrangements serve to circumvent hierarchies, strategize and act horizontally toward inclusion, while also lowering the cost of participation (Dahlberg-Grundberg, 2016; Earl and Kimport, 2011). Rather than being part of a formal system, participation is here seen as a way to work in parallel towards shared goals and issues that are negotiated by scattered publics, where consideration of differences and conflicts is an important condition for development. To understand how different factors such as autonomy and control have played a role for the super-taggers in an image crowdsourcing project in the 
cultural heritage sector, this case study employs a mixed-methods approach, consisting of semi-structured interviews and interface studies.

Our starting point is Kbhbilleder.dk in Denmark where crowdsourcing has been used to collect metadata for Copenhagen's historical images. Kbhbilleder. dk was launched in 2016 as a collaboration between the City of Copenhagen, the Copenhagen Museum, the Copenhagen City Archives, Nikolaj Kunsthall and Thorvaldsens Museum. The site showcases historical photographs from the Copenhagen Museum, the Copenhagen City Archives, Frederiksberg City Archives and the Magasin du Nord Museum, as well as maps and drawings. More material is being added continuously as the collections are digitized. The collections mainly contain material from and about Copenhagen and Frederiksberg, although images related to other places can also be found.

A number of studies have reported that citizen scientists tend to be in their 50s or older, have some college education, and are wealthy (Jones et al. 2018). This is in line with studies on volunteer work in general (Edwards 2016). However, when it comes to gender, this varies from area to area. Not unexpectedly, it seems to follow a traditional gendered structure based on interests (Edwards 2016). Our group of super-taggers at Kbhbilleder.dk confirms this pattern. They are by no means representative of users at large but represent those who are most closely involved in the work, and who can be seen as a kind of self-selected elite. However, they are representative as regards the tagging practices and resulting tags, as they have produced the vast majority of all the tagging in the system. To gain a perspective on their tagging practices, we conducted semi-structured interviews of about 50-60 minutes with eight of these super-taggers, supplementing the results with further questions via email. In the interviews, we asked questions about:

- their professional and personal background

- their motivation in relation to other interests

- their use of Kbhbilleder.dk:

o how they perceived the interface

o relations to other taggers

- other circumstances that were important for the tagging.

In addition to these interviews, we conducted an interview with the project coordinator about her experiences of organizing and developing the crowdsourcing platform.

The interviews were recorded, annotated in sound editing software and partly transcribed. All data were in Swedish and Danish, thus the quotes presented in the following have been translated into English. A thematic analysis was used to explore themes in the material through open coding, but also predefined codes was used to tag instances where interviewees communicated motivation, 
autonomy and control. These codes were clustered into conceptual categories during second order coding. This iterative process alternated with the investigation of theories that fit the emerging interpretation (Saldaña 2009). The findings were validated by sending the results back to the interviewees for review.

In addition to these interviews we have had access to anonymized user data from Kbhbilleder.dk which shows usage statistics from 2017, 2018 and 2019.

Based on the results of the interviews, we conducted an interface analysis of related infrastructure that the participants mentioned as important in the interviews (see Tables 2 and 3), and in this article we foremost focus on a comparison between the Facebook group which was the most used interface and the institution's interface Kbhbilleder.dk. Here we have used Hansson et al.'s (2018) typology of alienation and relationship in crowdsourcing to analyze the support for participation and levels of engagement in the interfaces where the four relationships Marx suggests are described on a scale from alienation to strong relationships, where the outer circle in Figure 1 represents high degree of alienation, and the center of the circle represents a close relationship.

To enable a deeper understanding of these tools, we created active user identities. We explored the interactive as well as the social dimensions of the interfaces by engaging with it in various ways during a three-month period, creating profiles, uploading data, participating in groups, and so on. These interactions were observed and documented in screenshots and notes.

\section{Results}

Kbhbilleder.dk was launched in November 2016 as a database and in October 2017 it became possible for the public to edit by tagging photographs with subject words and by placing images on a map of Copenhagen. In January 2020 there were more than 100000 images in the database and 2432 registered user accounts on the site, of which 652 have contributed with at least one edit. The majority of the accounts have not made any edits but may have contributed comments; 388 accounts have made between 2 and 100 edits, and just 28 accounts have made at least 1000 edits (see Table 1). In addition, over 8000 comments or corrections have been sent to the webmaster.

Since its launch in October 2017 up to January 2020, users have made 1102 260 edits in the form of an added topic word or placement on a map. Of those user accounts, the seven most active account for $94 \%$ of all edits. Thus, it is a very small group that accounts for most of the work. Just one person among these has made $71 \%$ (i.e. 782128 edits). That the crowd generally has a core of more dedicated users who carry most of the workload corresponds with previous research (Benoit 2017; Springer et al. 2008).

The participants in the interview study came from the groups that made at least 1,000 edits including those seven individuals who had made more than 
Table 1. Of the 2432 user accounts, 1780 never did any edits, 173 did one edit, 388 did 2-100 edits, 63 101-1 000, 221 001-10 000 and 7 user accounts did more than 10000 edits.

\begin{tabular}{llll}
\hline 1,780 & user accounts $=0$ & 0 edits & $0.00 \%$ \\
173 & user accounts $=1$ & 173 edits & $0.02 \%$ \\
388 & user accounts $>1$ & 5,148 edits & $0.47 \%$ \\
63 & user accounts $>100$ & 13,706 edits & $1.24 \%$ \\
22 & user accounts $>1000$ & 48,870 edits & $4.43 \%$ \\
7 & user accounts $>10000$ & $1,034,363$ edits & $93.84 \%$ \\
2,433 & user accounts in total & $1,102,260$ edits & in total \\
\hline
\end{tabular}

Table 2. Discussion groups online, informal archives, used by super-taggers to find information and discuss their findings, number of members 2020-01-21, and privacy settings. All groups are on Facebook except for 'Danske Slægtsforskere', which is on the website slaegt.dk discussion board.

\begin{tabular}{lll}
\hline Online discussion groups & Number of members & Accessibility \\
\hline Gamle København og omegn & 191 & public Facebook \\
De Gamle Nørrebro & 678 & private Facebook \\
Amagerbro skole og Islands Brygge skole & 1,005 & private Facebook \\
Gamle postkort & 1,021 & public Facebook \\
København under besættelsen (1940-1945) & 1,076 & public Facebook \\
Vi bruger Rigsarkivet & 2,126 & private Facebook \\
Amagers gader og stræder & 2,137 & private Facebook \\
Vi snakker om kbhbilleder.dk & 2,432 & private Facebook \\
København før og nu & 2,749 & public Facebook \\
Gamle Forretningsfacade & 3,010 & private Facebook \\
Vores Østerbro & 3,863 & private Facebook \\
Københavns omegn & 4,104 & public Facebook \\
Besættelsen 1940-1945 & 6,401 & private Facebook \\
Nørrebro før og nu & 8,700 & private Facebook \\
Danske Slægtsforskere & 11,815 & public slaegt.dk \\
Slægtsforskning & 20,483 & public Facebook \\
Gamle Kobenhavn & 59,856 & public Facebook \\
\hline
\end{tabular}

Table 3. Online formal archives the super-taggers used beyond Kbhbilleder.dk.

\begin{tabular}{ll}
\hline DetKgl. Bibliotek & https://www.kb.dk \\
Københavns Museum & https://cphmuseum.kk.dk \\
Kœpenhamns stadsarkiv & https://www.kbharkiv.dk/ \\
Vesterbrokorten & https://kortviseren.dk/vesterbrokortet/ \\
Arkiv.dk & https://arkiv.dk \\
Danmark sett fra luften & http://www5.kb.dk/danmarksetfraluften/ \\
Nationalmuseets Samlingar & https://samlinger.natmus.dk/ \\
Østerbro lille Museum & https://www.detlillemuseum.dk \\
Family search & https://www.familysearch.org/en/ \\
MyHeritage & https://www.myheritage.com/ \\
\hline
\end{tabular}


10,000 edits. They estimated that they spent between 10 and 100 hours a month on Kbhbilleder.dk. It is therefore not surprising that the majority are not gainfully employed, due to age or other reasons, and are between the ages of 53 and 77.

Of the eight interviewees, six were men and two were women. Their backgrounds vary both in terms of educational level and profession, but something they have in common is not only a great interest in local history and cultural history in general but an interest in images, either in photography, in having had an artistic education, or simply being interested in art or architecture. Prior to being involved in Kbhbilleder.dk, several of them were already active in other related forums, such as the discussion group Gamle København (Old Copenhagen), or in other crowdsourcing projects such as the City Archives transcription project Politiets registerblad (Police Register Sheets) and København begravelseprotokoller (Copenhagen Funeral Protocols).

\subsection{Managing khbilleder.dk}

In order to recruit a crowd to Kbhbilleder.dk, the coordinator first searched the Facebook group Gamle København and headhunted a group of historically interested Copenhageners, whom she thought were particularly knowledgeable and active. The invited taggers were selected from among those whose Facebook comments were attuned to historical data and knowledge sharing, rather than those offering subjective remarks about the images. The headhunted taggers were invited to a meeting where they could contribute their views on the project. The intention was that members of this group would serve as ambassadors for the project. Acknowledging the competence of this group by inviting them in this manner paid off. Several participants today form the core group of super-taggers who have, to date, done most of the tagging on Kbhbilleder.dk.

Regarding the City Archive, the purpose behind the crowdsourcing project was to obtain more resources, as it only had enough to digitize and publish the images, but not to describe the images themselves in any detail. However, the project coordinator (the strategist behind the City Archive's other digitization projects), not only views the users as free labor, but believes that it is as much about acquiring a variety of perspectives on the images, and a broader expertise that is not readily found in the archive's organization. She explained that if they had a couple of full-time employees doing the job instead, it would not be the same, no matter how knowledgeable they were, as they would not be able to replace the diversity and expertise that the crowdsourcing provided.

I don't think it would be possible to hire so many people. I think having someone who can assure the quality of the data in combination with a crowd that provides diversity is what gives the best metadata. Employees cannot manage so well without volunteers. They have so many different special interests, and that nerdy knowledge cannot be employed. It may be people who specialize in metal, or sewage, or 
whatever, who have developed deep knowledge of this. It is this combination of people with different special interests that is interesting. (Project coordinator)

In addition to this benefit of using volunteers, the project is also about creating engagement in the cultural heritage institution, and this project responds to the ambition of making the institution meaningful in a larger societal perspective.

At present there is only one person working with the volunteers, but the coordinator thinks it would be better if a group of registrars were to work with them as she thinks it is important to have enough people who can provide feedback and engage with the volunteers. She believes it is important to meet the taggers' commitment with an equal commitment, and that they should have a mutual interest in the work, thus emphasizing a peer-relation rather than a controlling function.

Currently, most feedback and changes go through the archive coordinator, which creates a bottleneck for the project. Discussions with participants at Kbhbilleder.dk mostly take place via email and on the project's Facebook group. Some of the work with giving feedback has been delegated to one of the supertaggers who is now the administrator of the Facebook group. In this group the users have an opportunity to discuss the use of Kbhbilleder.dk in the absence of discussion opportunities in the crowdsourcing tool itself. In addition to this forum, the City Archive organizes annual events, with users invited to lectures and discussions. To highlight and reward the individuals who contribute the most, the 25 most productive accounts on the website are also named in a public top list. Thus, from the perspective of the City Archives, a good dialogue with the participants is important for supporting existing interest and commitment, where they have primarily turned to local historically interested individuals. This dialogue is also highlighted as vital by the participants in the interview study.

\subsection{Participant motivation}

\subsubsection{The relation to oneself; identity, competence, and the enjoyment of learning}

When we ask the participants how they started with crowdsourcing and why they continue, we find that their motivation is, not surprisingly (as they were recruited for this reason) because they are interested in and connected to their local history; it is thus about strengthening identity and the relation to oneself. They often have a lifelong interest in history and a personal relationship to a certain place or area. Several participants also mentioned a great interest in images, and many are active photographers.

From the time I learned to walk, I was dragged around the streets of Copenhagen by my mother's aunt Inger, who lived on Østerbrogade (overlooking the lakes), she contributed to the love I have for Copenhagen today. Aunt Inger took me out to ride the tram, so I was out riding the last tram that was driving in Copenhagen before they disappeared. 
I am still able to hear Aunt Inger's voice as I walk in Copenhagen: 'LOOK UP! - look past the advertisements, look at the ornament, look at the building details, see how they have done the details!' etc. In addition, my grandfather - who was an amateur photographer and who taught photography where he worked as a teacher - taught me to see the details in images.

These two people have given me a fascination for images - also the old Copenhagen.

I have always been fascinated by images, but also the old Copenhagen, and therefore I believe it is of the utmost importance that the images from the archives become searchable for future generations.

For starters, I was looking for locations where my own family has lived and worked. (Participant G)

The crowdsourcing is also very satisfying, and is a way to keep the intellect alive. One participant mentions that they prefer difficult problems and exciting photographs. One key reason why images are important for the participants is because they can be so complex. Thus, the activity confirms their competence. But image management can also provide inspiration for an individual's own artistic activities, and self-actualization:

I see my world in images, and am also an amateur photographer, so in addition to the historical aspects, I also get new inspiration for new motifs and angles. (Participant G)

One participant pointed out that the act of tagging an image also means looking more closely at the image, i.e. seeing more, and that the tagging thus becomes a 'viewing tool'.

\subsubsection{Relationship with peers: Duty and community}

Confirming previous research (see e.g. Oomen and Aroyo, 2011; Ridge, 2013), we found that being connected to a social and historical context was also a strong motivation for the participants; it was about doing good for the greater community and making a contribution to society and the future.

Through my participation, I try to make it easier for my fellow people to find their own history and to understand the images that are available to Copenhagen and Frederiksberg. (Participant F)

It gives me immense satisfaction to know that for each image I put the subject/location or submit 'info' etc., the image may give others (and future generations) a positive experience of our shared history. (Participant G)

Words such as duty and obligation are frequently used, and statements about wanting to contribute to society with the knowledge one has accumulated, perhaps from a long working life, or skills acquired. Therefore, participation 
strengthens a person's identity and feeling of connectedness with their inner values and a larger context, while they also experience the enjoyment of putting their knowledge to use.

I think the archive work is fun and exciting, and I like to use my knowledge and experience for common use. This applies to linguistic competencies (English, French, German, Latin and not least Old Danish) and the cultural-historical knowledge that I have accumulated through many years of reading everything and many years of work in a library. (Participant E)

Another motivating factor was the importance, to many, of being part of a collective knowledge production and so being in direct relation with other producers. Facebook groups like Gamle København, in particular, consist of a large number of people with different special interests who are generous with their knowledge:

What [motivates] is, for most of [the members at Gamle København] is their interest in history, and the joy of sharing their knowledge with others. That motivates many. There are an incredible number who know what you are looking for. They are simply experts. And no one is afraid to say that they don't know. But all of them are motivated by the joy of sharing, they would love to tell and share their knowledge. There is no one in the groups who thinks they know better and who would beat me. Everyone is happy to share. (Participant B)

The majority of the participants were involved in several different contexts, which in various ways helped to develop the collective work and their individual interests. Kbhbilleder.dk are just a small part of this production system. A few, however, tagged more mechanically and took pleasure in solving simpler tasks. Here the content of the task was less important; participants took on what was closest, and that which was unfinished. But the vast majority also contributed to the archives because of a particular interest, or a particular neighborhood, and were not primarily interested in the tagging itself but rather as part of a larger personal investigation. This corresponds with previous research showing how simpler micro-tasks might, for the participants, be just a part in a larger interest and process of learning (Raddick et al. 2010; Reed et al. 2013).

The desire to find a social community is mentioned as important in a couple of cases. As our participants were in most cases retired, their motivation could be to replace a paid-work community with another type of work community. In these communities they are potentially both consumers and producers, and the difference between these roles is small. As those who 
consume the information also are producers and members of the community there are direct relations between consumers and producers.

\subsubsection{Scores and money devaluate relationships}

When we ask participants how much time they spend, it varies from a couple of hours a day to one day a month. The coordinator noted that if participants were paid for their time, they would inevitably be underpaid, as the institution could not possibly pay fair wages, and then their work would receive less value. Rather than receiving valuable and appreciated volunteering, it would be simply an underpaid job. She therefore believed that payment is neither possible nor desirable.

The need for this work to remain unpaid was emphasized by everyone as payment might even devalue the work, according to the majority. For example, it could result in decreased autonomy, or might result in a deteriorating sharing culture, as it would set people against each other, destroying relations. In Marx's terminology, instead of working for the enjoyment of the work, the product would be mediated by money or a score, which is creating distance between the producer and the product.

Only one of the interviewed super-taggers admitted to an economic incentive, seeing this volunteer work as a way of gaining experience and credibility that might generate paid work in the long run. However, such an incentive is not primarily about charging for work, rather it can be seen as a way to rationalize a behavior in a society where being unemployed is a stigma. Engagement in volunteer work is also a widespread practice in Denmark.

[What would happen if you got paid?] Then I think many would quit. Because they simply expect a certain working relationship. I do not want to be bound, if I have to spend 2 hours instead of when I feel like. [ ... ] I think it's important that it be voluntary. (Participant D)

Conflicts? No, everyone is generous. No one wants special cred. It is probably because there is no money involved. You don't need cred. (Participant B)

It was not only payment that was debated, the scoring system on Kbhbilleder. $\mathrm{dk}$ was also questioned. Here, many thought it was good to be able to revisit what you had done yourself, to be able to retrieve previous tags and develop them. However, there was no interest in sharing accomplishments openly and no desire to compare numbers of points with other participants.

[What do you think about the scoring system and ranking on kbhbilleder. $\mathrm{dk}$ ? Do you understand how it works? Is it important to you?]

I think it should be abolished. Editing should be a pleasure, it is not when it turns into a competition, so no it is not important to me. (Participant F) 
Several participants discussed how this system created incentives for competition that rewarded quantity rather than quality. The problem was that some users quickly accumulated high points by tagging what the critics thought were staple details in the image collection, like 'window' or 'street' in a city archive like Kbhbilleder.dk, instead of reflecting more carefully on what subject words were relevant to finding the image. The scoring system was also felt to be misleading, as some participants did a lot of research to determine, for example, location or age, while others only outlined descriptors in the image in tags such as 'car' or 'child'. It was felt that such points were too easily earned.

In summary, the results correspond with previous research that points to interests, self-actualization, altruism and community as major motivational factors (see e.g. Aucott, 2019; Bonacchi, 2019; Oomen, 2011; Terras, 2011). To describe it in terms of relations: it was the relation to oneself and the work that was most important for the participants. It was about self-actualization by strengthening one's self-identity as competent, while also being creative and learning new things, as well as satisfaction with the work itself, which is exciting and satisfying to perform. In addition, there was a sense of belonging to a larger community where you felt satisfaction in contributing to society. Another motivation was the relation to peers, and the satisfaction of being part of the collective knowledge creation in a heterogeneous and loosely linked work community where questions could be quickly answered. The social community with other people interested in history was important to some people who also met in real life.

Only one of the interviewees did the work to gain a high score or to achieve a social position. A few people appreciated that the scoring system gave them clear feedback on what they were doing, but several found that the disadvantages of the system were greater than the benefits, as the work became predictable and quantity was rewarded ahead of quality.

\subsection{Crowdsourcing in a wider context}

Kbhbilleder.dk was the common denominator for the participants in our study, but the site is only one part of a larger ecosystem of archives, discussion groups and physical contexts, which in various ways contribute to the work of tagging images. Image tagging is also not the main interest of the participants, but secondary to their common interest in local history:

Yes, those [super-taggers] are in more places than Kbhbilleder.dk, they are also involved in other contexts. Their interest is in history and Copenhagen. I can see that the same people who are on kbhbilleder.dk are also part of many of the other groups. [...] And we sometimes meet. (Participant B)

Tables 2 and 3 list the online discussion forums and other archives that participants mentioned as important for their image-tagging work. 
Several of the participants in the study contributed to crowdsourcing projects other than Kbhbilleder.dk, such as the transcription project The Police Register (Politiets Registerblade) and the Copenhagen Funeral Protocols (+ på danska - om konsekvent), which are also run by the Copenhagen City Archives. International genealogy sites like MyHeritage are also about users contributing their data. The tagging tool itself on Kbhbilleder.dk lacked a space for discussion. It was not possible to see which user did what, or any description of why. Discussions were referred to the Facebook page 'Vi snakker om kbhbilleder.dk' (We talk about kbhbilleder.dk), with 2,432 users. Here you could ask other users questions and discuss difficult images.

But if you wanted a really quick answers about an image, the Facebook group Gamle København was highlighted as the best source to find help with an image that was difficult to place or identify. Almost 60,000 members gathered here, so there was always someone who had time to respond. The private group København Før og Nu (Copenhagen then and now) with 2,749 members, included many participants who were also active on Kbhbilleder.dk. Often, it was the combined expertise of these groups that was helpful in finding ways to define an image, such as placing it in the right context or, for example, dating an image. The relations to people in these contexts were highly valued:

In these forums, there are the best railroad people, the best tramway people, they are in these groups. The tramway people can date a photograph from a lamp, so they can narrow it down, for instance, this lamp it came in March 1912 to October 1912. That way they can know exactly when this image is from.

[So then do you meet people from different professions?]

Yes, it's super exciting. It can also be like skirts, how to sew something, then you can date an image based on a woman's [dress]. (Participant $\mathrm{H}$ )

Many of the super-taggers viewed this collective detective work as the aspect that made the work so exciting. Some users had a social network around the interest offline, while others only discussed it online.

On my 'main projects', especially the Police Register Sheets, I work closely with a few other volunteers, but I am not directly in touch with others at kbhbilleder.dk. Occasionally I have asked questions on the project's Facebook page 'We talk about kbhbilleder.dk', and here I have virtually met other contributors, especially some men whose knowledge of technology, shipping etc. are in completely different fields than mine. It is good that we have different backgrounds and can contribute differently. (Participant E)

The discussion forum brought together people with a common interest in historical images, but that does not mean that they had a common perspective, rather 
it is precisely the different particularities and special interests of each participant that was innovative.

\subsection{Personal archives; agency and purpose.}

Most participants also had a well-developed special museological interest or hobby, and several created their own collections and publications. This might include systematically collecting all their relatives' images and digitizing them. Two of the super-taggers had written a book about their special interest, and a third had not only created a digital archive online but also created a physical museum. One of the super-taggers manages the local museum in his neighborhood, and another works professionally at a museum. The most technically advanced super-tagger had developed a site where he linked different databases into an interface that combines images and maps from different time periods.

Yet another super-tagger created more overarching thematic categories - on a higher abstraction level than the commonly very descriptive, denotative tags - such as 'children in hospital' or 'women at work'. These categories stemmed from her own interest, highlighting alternative narratives about the role of women and children in history.

When you look more closely at photographs that appear in the largest Facebook group Gamle København, it is evident that private collections, commonly appear, on a smaller or larger scale. Such photographs, for example, may be drawn from personal photography such as in Figure 2, a documentation of Ello Magnussen's orchestra, or photographs digitized from an anniversary book made

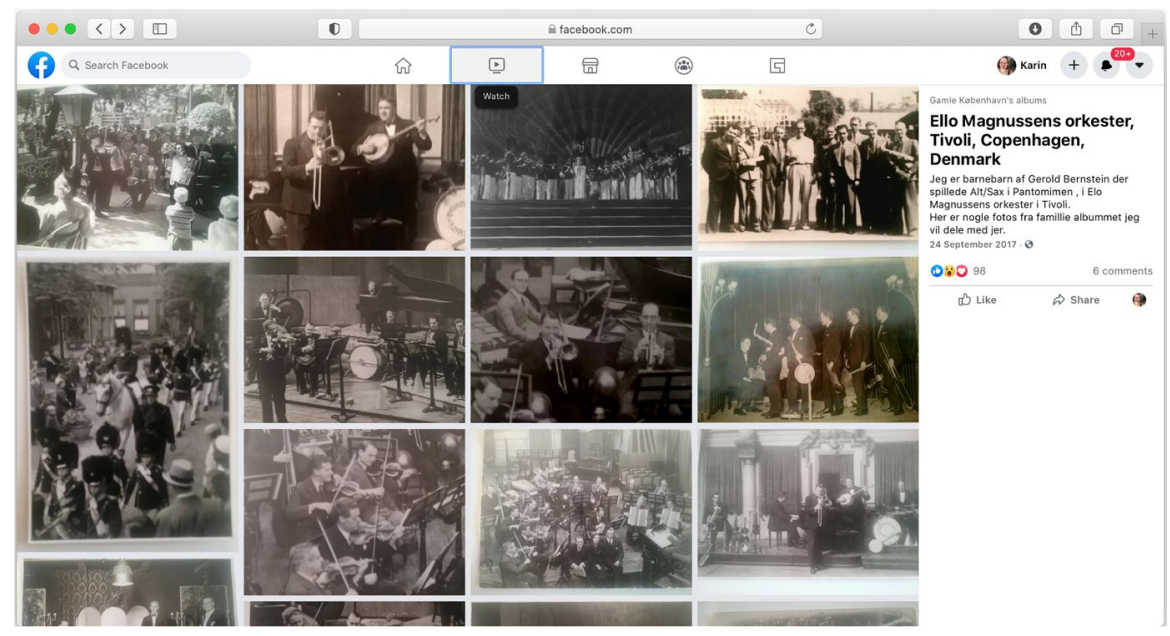

Figure 2. Photo album from the Facebook group Gamle København [Old Copenhagen]: Ello Magnussen's orchestra 


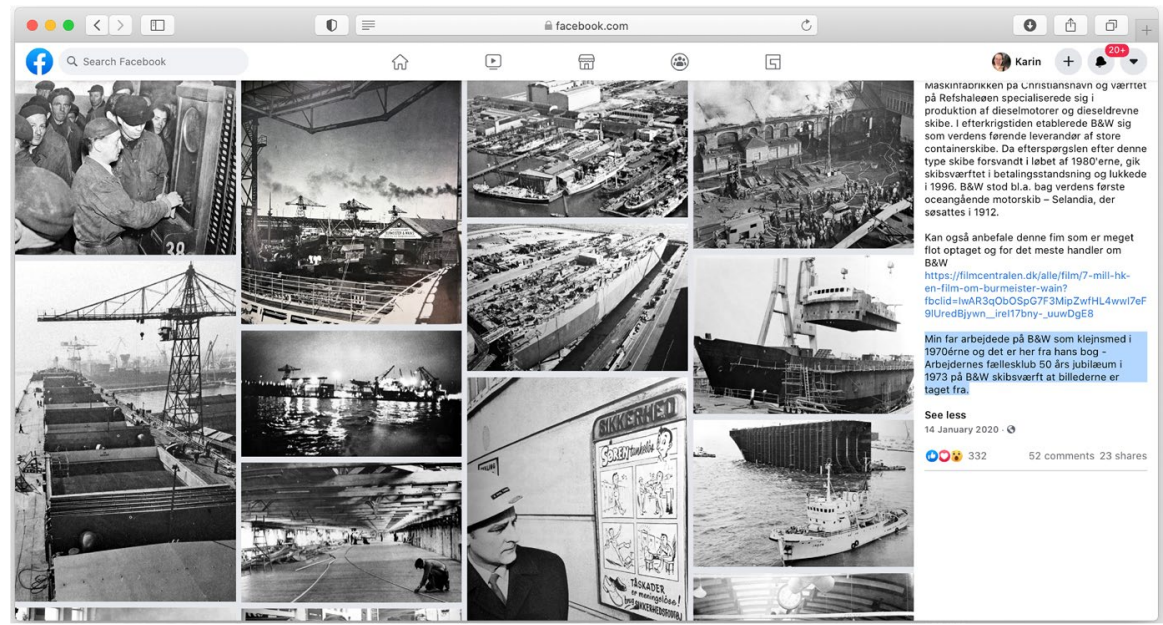

Figure 3. Photo album on the Facebook group Gamle København [Old Copenhagen] consisting of photographs from the book 'Arbejdernes commion club 50th anniversary in 1973 at B\&W Shipyard'

by someone's father, as in Figure 3: 'Arbejdernes commion club 50th anniversary in 1973 at B\&W Shipyard'.

The Facebook group Gamle København also contained images from public databases such as Kbhbilleder.dk or kb.dk (the National Library of Denmark). Conversations were most often about photographs that someone wanted to discuss for some reason, like getting help to determine when it was taken and/or at what location. Overall, a large collection of images was created in this way, composed of almost 67,000 photographs, in just one Facebook group. This can be compared to Kbhbilleder.dk's 100,000 images. On Facebook, images were also richly described through the forum's discussions (see Figure 4). Unfortunately, it was difficult to search and navigate this collection of images, as Facebook's interface didn't allow it. Thus, what the whole Kbhbilleder.dk project was about, making photographs searchable with textual metadata, is a feature that was completely absent in the Facebook interface. Back logging, searching into the past was not built into the Facebook user interface at all, while being the default feature of any formal image archive, analogue or digital.

In sum, our interviews demonstrate that the super-taggers were strong subjects with agency and purpose, that sometimes created their own collections and moved across multiple interfaces and social contexts to carry out the work of defining images. Here, they confronted the various possibilities and limitations of the interface, in deciding which strategy to take to fulfill their personal "agenda". 
Crowdsourcing historical photographs: autonomy and control...

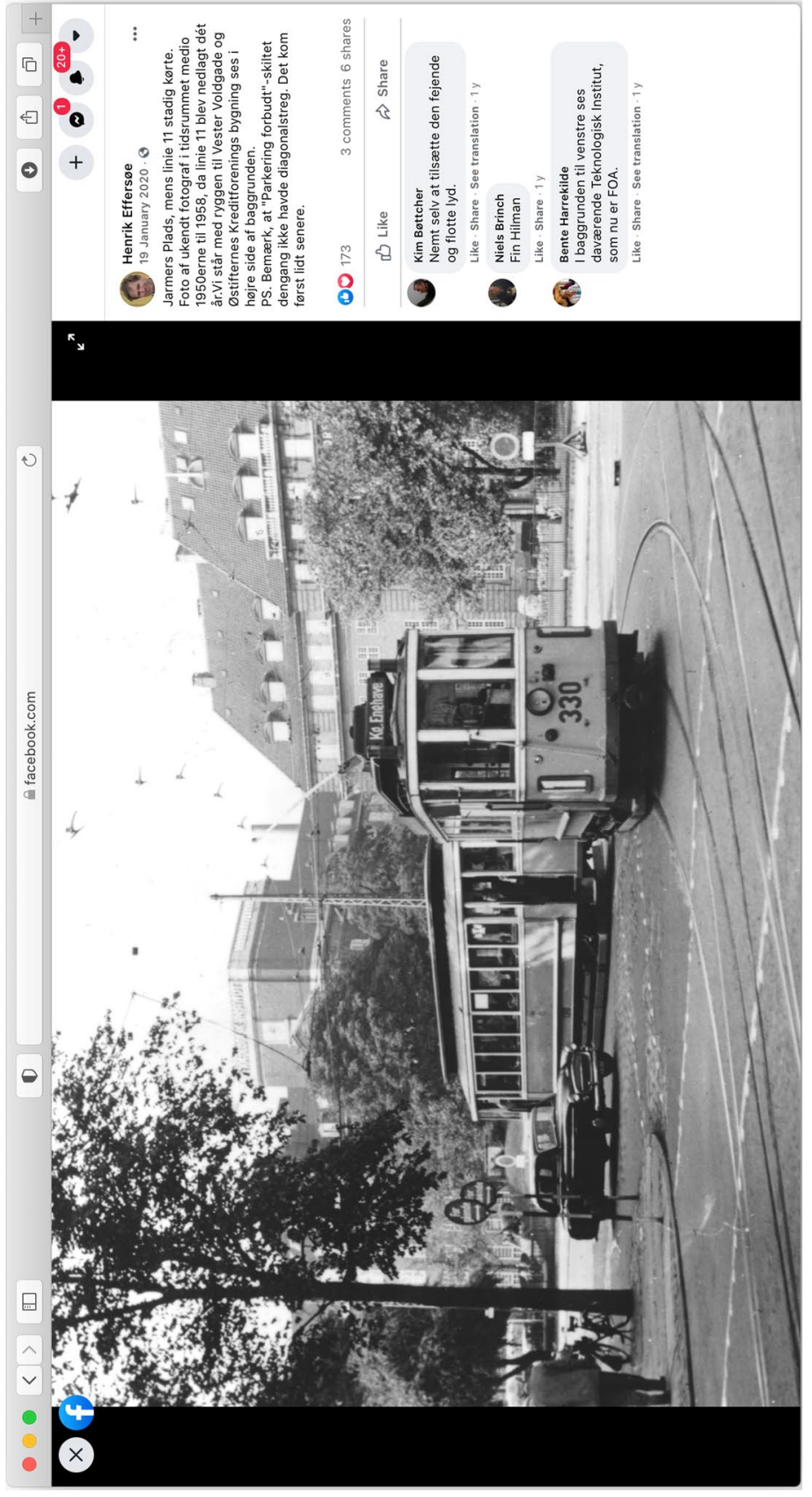

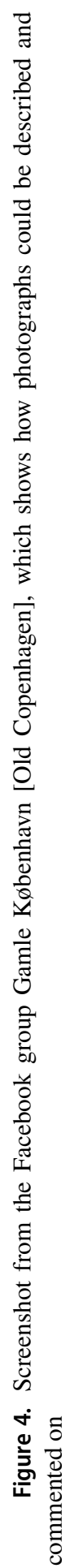



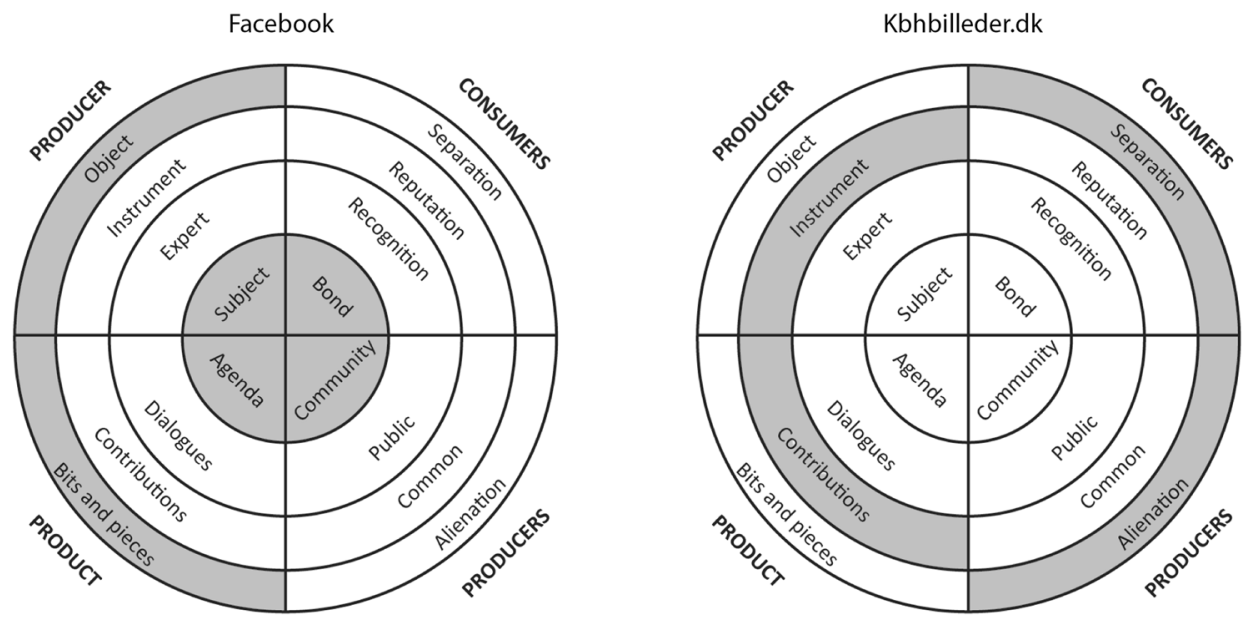

Figure 5. Interface support for alienation and relationships in Facebook compared to Kbhbilleder.dk

\subsection{Support for relationships in a Facebook group compared to Kbhbilleder.dk}

The interviewees emphasized the importance of the relationship to a larger historical context. At the same time, relationships with other crowd workers were also appreciated, although this could involve conflicts. Kbhbilleder and the Facebook group exemplify how various interfaces enable different kinds of data production and working relationships. When comparing the functionality of a Facebook group with Kbhbilleder.dk according to which relationships are supported, it was seen that these two interfaces were far apart, as illustrated in Figure 5. The Facebook group emphasized the participant/producer relationship with themselves, in that this forum promoted the participants' expression of their interests and subjectivity through various activities (status updates, posts, references) that were clearly linked to the user. In contrast, participants produced without their knowledge amounts of data that were not made transparent, such as data about their behavior, relationships and preferences. Here the participant/producer became more of an object, where the data is mined without participant's consent, as pointed out by Andrejevic (2011) and Scholz (2013). However, our informants didn't express any problems with social media in this aspect, rather it was the other users that could be perceived as a problem.

Kbhbilleder.dk contained a profile page where the users/producers could see the fruits of their work, but the opportunities for self-expression were more limited. By seeing the images they work with, and how, the user could see the result of their actions. However, much of the information that was produced was not made transparent on the site. For example, it was not easy to search which images had been tagged, or get an overview of the work done by a particular tagger. The 
user's subjectivity was thus ignored, instead the user was more like an instrument, a tool for someone else's intentions.

The relationships between the producers were supported by the interface in Facebook. Although a certain value was added to the user's activity (number of friends, likes, etc.), this was not something that the participants directly compared, instead it was the community and the sharing which was emphasized in the interviews.

The support for relationships between those who produce and those who consume was most evident in the private Facebook groups. Here you had to be a member, and thus present a profile, in order to access the results of the discussions in the forum. Therefore, the producers were sometimes the same as the consumers of the information, and had the potential to create bonds, knowing who was there, as they had a path of communication to each other and the forums were not too large. Unlike this, the relationships between users are not promoted on Kbhbilleder.dk. It was not possible to see who produced the tags on an object, so those who used and those who produced tags remained anonymous and unconnected.

The relationship between the user and their own work was trickier to define. For what work is the user doing in these contexts? If we assume that the work was intended to produce context and discourse for a particular image, then both interfaces have some support for this. It is possible to see the connection between the individual's special expertise and the work they did. In the Facebook group, the discussion forum created an opportunity for a more self-centered deliberation that was governed by the user's interest and agenda. The knowledge that was clearly generated can be derived from the experience and skills in particular subjects. Quality was rewarded by appreciating other users through comments and likes. At the same time, the users contributed to a user data collection over which they had no control, where Facebook collected bits and pieces of information about the users' activity.

In the crowdsourcing interface at Kbhbilleder.dk, the tagging did not always require expert knowledge, but could be done by someone with a basic education and cognitive abilities, who could contribute with descriptions on a denotative level, simply putting 'what can be seen in the image'. Kbhbilleder.dk and the Facebook group were thus far apart, considering how working relationships were supported by the interface.

\subsubsection{Conflicts: score, nostalgia and political ideology}

Similarities between the interfaces highlighted by several of the interviewees included the good mood, the lack of conflicts on Kbhbilleder.dk and the great generosity of the participants in various Facebook forums. Kbhbilleder.dk was very open and easy to enter - and potentially to destroy, by removing tags and entering incorrect information. But this rarely happened, so the coordinator at 
Kbhbilleder.dk has had no reason to embed more security features in the system, and could handle any issues with the help of the users reporting errors directly to the administrator.

One of the few conflicts spontaneously raised by several of the interviewed super-taggers was specific to the scoring system and how it could reward distorted, even meaningless tagging. The critics argued that instead of having a qualitative dialogue, the interface rewarded quantity over quality (for which Kbhbilleder.dk had no method of measurement). The scoring system was independent of the quality of the tags, with the one with the most tags winning, no matter how insignificant or even detrimental for the usability of the platform.

The majority of the participants had a great deal of experience in traditional archiving, and they thought it was important to choose the core subject words, and not too many, to describe an image. A few described all the depicted objects in the photographs with several synonyms, both plural and singular. The latter way of tagging easily created an inflation in tags, which can make the search more difficult by providing too many hits in a search result, according to some participants. On the other hand, an overly sparse topic categorization of images may prevent other types of searches from being possible. This worried most quality-oriented taggers. Since the participants themselves cannot see exactly who have done what in the system, it meant that they could not discuss topics directly with each other. The only action possible was to edit a tag you did not agree with, which might lead to some irritation that the site's administrator then had to resolve if it was not disclosed in the Facebook group. In this case, one can say that the lack of discussion in connection with the tagging function made solutions to conflicts more difficult, while at the same time the people involved did not have to confront each other directly and the conflict could not escalate. However, in terms of knowledge development this invisibility between the different taggers hindered collective learning. Each tagger acted as if they were in their own universe in Kbhbilleder.dk.

In an open Facebook group, discussion can become sensitive and create further conflicts. Just because you have a common interest in, for example, street names, does not necessarily mean that you feel the same about other issues. A couple of the participants mentioned that they sometimes found it difficult to feel part of the community on some of the Facebook groups. The reasons given were around too much nostalgia, and that 'it was better before'. One person also mentioned that the discussion could be dominated by ideologies he did not want to be associated with, which is why he never actively participated in the discussion in any groups but only read other people's posts.

I'm not posting anything. [but you read there?]. I just read what others have written. Also because I ... most of it is that everything was better before. It's a 
little comical. [...] And there are some discussions that border on racism. You should not interfere with such things. (Participant I)

One participant, also the moderator of several Facebook groups, felt that an element of his work in these groups was to halt discussions of a political nature, in order to avoid conflicts.

In summary, the super-taggers moved across multiple interfaces and social contexts in the course of their work describing images, from smaller formal, public and local interfaces such as the Copenhagen City Archives and the National Museum, to larger informal, private and globally situated contexts such as groups on Facebook and genealogy sites such as MyHeritage. They also moved between large-scale collective archive work and smaller personally connected collections. What connected people in different discussion groups were narrow special interests, such as local history, street names, architecture, World War II or genealogy. These groups might be narrow but they were distributed globally as, for example, international genealogy contexts. Here, it was mainly language barriers such as Danish and English that restricted participation. Within these interest groups, the participants might be very different, for example, in terms of their work objectives or political ideology. Conflicts could arise in different discussion groups, or there might be areas for potential conflicts that participants expected, which meant that some people simply avoided participating more actively.

Above all, participation required a great deal of commitment. Decisions about what was tagged, or not tagged, was largely controlled by the participants' special interests. But discussion in the Facebook groups also delivered a consensus on how an image should be tagged, and methodologies for how those images could be determined, where this collective puzzle work was important. The individual's special knowledge and interest, combined with a digital literacy that combines traditional information seeking with a deliberative knowledge development, was thus what constituted the production relations around Kbhbilleder.dk.

\section{Concluding discussion}

This study of a crowdsourcing context in Denmark contributes to a better understanding of the production relations in participatory archiving practices in the GLAM sector in terms of power and control, by describing how crowdsourcing participants' relations to themselves, their work and other participants were supported in different types of online interfaces, social settings and ideas of archiving, that together created the structure for this collaboration. Unlike previous studies, foremost focusing on single interfaces, this study illustrates that connected networks between different online interfaces, and the interlinked character 
of online and offline communities and institutions, can be vital for how crowdsourcing initiatives function.

Our study reveals many similarities to previous research, showing that participants are driven by great interest and commitment, a desire for autonomy and learning, community, and belonging (see e.g., Aucott, 2019; Bonacchi, 2019; Brewer, 2016; Jones, 2018; Oomen, 2011; Rotman, 2012; Terras, 2011). But most importantly we point out that these driving forces can be understood in terms of power and agency. One of the biggest problems with crowdsourcing is to motivate participation, however, while for example autonomy and control are acknowledged as motivational factors in previous research, there is a lack of systematic analyzes of the participants' actual power over the work in relation to different systems. In this study we therefore provide a more holistic framework for analyzing participation in terms of power by focusing on how different relationships are accommodated.

The super-taggers' production of metadata on Kbhbilleder.dk was primarily motivated because it strengthens the participants relationships to themselves: The work strengthened their sense of being connected to a larger historical timeframe as well the feeling of joy in knowing that their competences were recognized and used for the benefit of others, while they also enjoyed the actual work, having a direct relationship with the product of their work. Satisfaction also came from being part of a collective work process, where the heterogeneous expertise of the group effectively solved 'image mysteries'. Thus, relationships with other producers seemed to be a central trigger, but also the quality or complexity of the task strengthening their feeling of competence. The more challenging the task the greater the interest it elicited among the super-taggers. Some super-taggers spontaneously constructed more advanced overarching categories even though this was not required or spelled out in the interface, thus regaining control that had been denied in the interface. The relationships with the consumers, other people interested in history, were important to a few participants, but this was not their main interest. Neither was motivation attributable to external awards. In fact, participants were even opposed to the gamification of work in the form of points or payment. This was not considered conducive to quality, and the comparison of points was detrimental to the relations with other super-taggers, which is interesting given the possibilities attributed to gamification in previous research. Furthermore, the commodification of relational data that takes place in social media settings, as pointed out by Andrejevic (2011) and Scholz (2013), was not seen as a problem by this group of users. Rather it was the relations to other users that was perceived as a potential threat, as differences in political views might prevent participation. 
The production conditions in the interfaces Kbhbilleder.dk and Facebook groups were at opposite ends of a relational scale but also complementary. On one hand, discursive collective processes in Facebook's interface emphasized relationships and dialogue, and the agency and subjectivity of the participant, which also made conflicts visible. On the other hand, there was a more instrumental collection of data on Kbhbilleder.dk without support for collective organization or social identification. This institution also created an archive that was intended to be sustainable and searchable over a long period of time, acknowledging a relation with past and future generations, which private social media companies such as Facebook do not take responsibility for. Any conflicts or ambiguities were referred to various Facebook forums.

Also, while the metadata produced in the institutions crowdsourcing interface enabled a diversity of readings of the same material, most of the supertaggers have simultaneously taken on the task of tagging the material according to traditional archiving, aiming for a shared standard of subject categories. Unlike the concerns expressed by van Hooland et al. (2011) that user-generated tagging might be creating a 'commodification of culture', placing greater value on current accessibility as opposed to future accessibility, this study shows how super-taggers can take great pains to ensure that the tags are historically sustainable.

What was collected at Kbhbilleder.dk is, like many other digital citizen sciences projects, data that was easy to divide into smaller parts and collect, where the focus is to retrieve images based on keywords. The more discursive and qualitatively richer work produced in different discussion groups, creating new relations to the images to different sources of information and personal reflections, was too extensive to fit within the archives' interface.

What is interesting is how the limitations of the systems forced more participatory processes to take place outside Kbhbilleder.dk, in discussion forums, mainly on Facebook. Here, alternative, informal archives continued to grow, consisting of participants' own collections or images from different public archives, like spontaneous information islands where data from different, more orderly, formal archives floated together enabling these databases to grow and compete with publicly financed and professionally structured databases. However, as the interface of the discussion groups were not searchable they created isolated islands of information around each image with no options for retrieval in retrospect, to link or group cohorts of images.

Our interface analysis showed how Kbhbilleder.dk could be seen as being in opposition to a Facebook group when it comes to supporting the individual's relationship to their own work. The Facebook group provided better support for relationships with the work and other producers. But this particular proximity can 


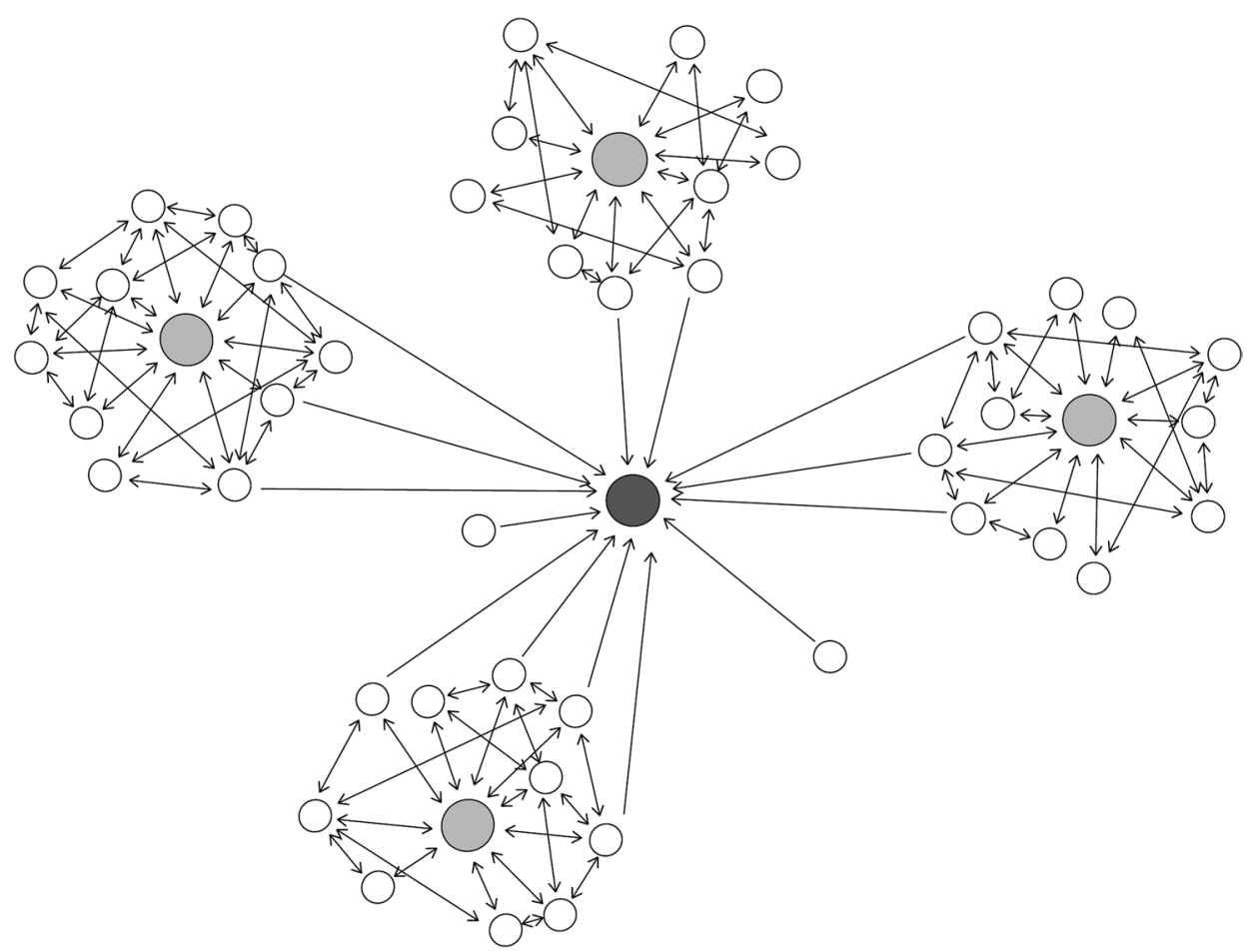

Figure 6. Relation between Kbhbilleder.dk (black dot in the center) with no communication between users (where the long term data collection took place) and more deliberative settings such as discussion groups online (where the development of data took place). The grey dots represent shared interests, the white dots are the participants, and the arrows represent the flow of information between participants, and between participants and the user interface

also seem to be exclusionary, since it requires a relatively homogeneous group to function without major conflicts. From this perspective, one can say that Kbhbilleder.dk's more instrumental way of dividing the work, which perhaps may seem to alienate the participants in many aspects, also has the effect of reducing potential conflicts and enabling the more inclusive participation of different types of groups. Unlike previous research on paid crowd work emphasizing the negative aspects of alienation due to lack of control over one's work conditions (Irani and Silberman, 2013; Martin et al., 2016), the implications for this type of volunteer work thus are different as they don't depend on the interface for an income from their work, instead it provides a seemingly neutral ground where the results 
of their work are stored. Because the development of various discourses about what constitutes 'right' metadata took place outside the interface itself, Kbhbilleder.dk did not express a preference for a specific way of describing images but allowed the crowds to develop their (sometimes contradictory) discourses on this in a variety of semi-public contexts (Figure 6).

In practice, however, most of this crowd work primarily took place not within the framework of the cultural heritage institution, but on private, informal, often corporately/commercially run discussion forums where it was the participants that were in control of the agenda.

This paradox, between alienation and inclusion in the crowdsourcing toll on the one hand, and community and exclusion in the discussion forums on the other, constitute the production relations in this case study. Probably this is something that public institutions, designing for a more participatory cultural heritage, need to consider to understand and support participation, while also acknowledging the differences and inequalities between and within different settings. These diverse and complementary aspects induce motivation to participate in different ways. In order to provide a neutral space for long-term archiving practices, where diverse groups can collaborate without too much conflict, a certain degree of system control and segregation between participants might be useful to ensure long term sustainability an user autonomy. But in order to provide a plurality of data, motivating participation of a diverse group of people with different perspectives, tightly controlled crowdsourcing systems are not participatory enough.

To attract and engage participants, cultural heritage institutions would first need to consider the opportunities to create direct connections between participants through the image metadata and, in addition, the opportunity to link private archives with the public cultural heritage. Given that super-taggers often are highly competent both as individuals and as a collective (Reed et al. 2013; Ridge 2013) cultural heritage institutions would benefit from enabling high level tasks for the crowd and not only simple micro-tasks. However, this 


\section{Appendix}

Table 4. Hansson et al.'s (2018) typology of alienation that was used to analyze the interfaces.

The relationship between the producer and the consumer

Separation

Reputation

Recognition

Bond

The relationship between the producer and the product

Bits and pieces

Contributions

Dialogues

Agenda:

The relationship within the producer

Object

Instrument

Expert

Subject

The relationship between producers

Alienation

Common denominators

Public

Community
No relationship

Producer or/and consumer might be displaying a certain reputation, the product/consumption is connected to a certain id.

Producer and consumer can acknowledge each other's existence, like e.g. through user names and user profiles.

Producer and consumer can get to know each other; there are support for communication like discussion forums and profile pages.

No relationship, the product is fragmented in bits and pieces so the producer has no connection to the whole.

Producer is producing clearly defined assignments, and there is not much room for creativity.

The result is the result ofa discussion.

The work is the expression by a strong subject.

The producer is a passive object.

Producer is an instrument producing clearly defined assignments.

The producer is an expert with a certain skill or ability.

The producer is a subject with agency and purpose.

Producer has no relationship with other producers.

Producer has a common interest.

The producer shares a public, a forum for expressing their opinions.

The producer has tools to establish a community with other producers.

has to be paired with extensive institutional support and guidelines where these super-taggers would serve as important co-producers who can develop their skills over time and within larger themes rather than in single projects. In addition, it is important to delegate some of the control in the interface, and thereby support participation. By looking at participation in terms of alienation and relationships, we also get a key to how to support participation in the system: by being observant of how different relationships can be supported and thus how to increase the degree of user control, increased participation and deeper engagement can be motivated. 
Finally, it is vital that cultural heritage institutions acknowledge and support the networked character of the heritage arena, not only connecting to other public institutions but also local, non-profit, as well as corporate agents in the field. This complex network of different agents online is the museum without walls of our times.

\section{Acknowledgments}

We would like to thank Signe Trolle Gronemann, Copenhagen City Archive, and the super taggers at Kbhbilleder.dk for sharing their experiences with us. The research for this article was conducted within the project Politics of Metadata (2018-01068) funded by The Swedish Research Council.

Funding Open access funding provided by Stockholm University.

\section{Declaration}

Conflict of interest The authors declared that they have no conflict of interest.

Open Access This article is licensed under a Creative Commons Attribution 4.0 International License, which permits use, sharing, adaptation, distribution and reproduction in any medium or format, as long as you give appropriate credit to the original author(s) and the source, provide a link to the Creative Commons licence, and indicate if changes were made. The images or other third party material in this article are included in the article's Creative Commons licence, unless indicated otherwise in a credit line to the material. If material is not included in the article's Creative Commons licence and your intended use is not permitted by statutory regulation or exceeds the permitted use, you will need to obtain permission directly from the copyright holder. To view a copy of this licence, visit http://creativecommons.org/licenses/by/4.0/.

\section{References}

Andrejevic, Mark B. (2011). Surveillance and alienation in the online economy. Surveillance \& Society, vol. 8, no. 3, 2011, pp. 278-287.

Aucott, Paula; Humphrey Southall; and Carol Ekinsmyth (2019). Citizen science through old maps: Volunteer motivations in the GB1900 gazetteer-building project. Historical Methods, vol. 52, no. 3, 2019, pp. 150-163.

Benoit, Edward (2017). Comparing domain expert and novice social tags in a minimally processed digital archives. American Archivist, vol. 80, no. 2, 2017, pp. 407-438.

Bevan, Andrew; Pett Daniel; Bonacchi Chiara; Adi Keinan-Schoonbaert; Daniel Lombraña González; Rachael Sparks; et al. (2014). Citizen archaeologists. Online collaborative research about the human past. Human Computation, vol. 1, no. 2, 2014, pp. 185-199. 
Björgvinsson, Erling; Pelle Ehn; and Per-Anders Hillgren (2012). Agonistic participatory design: working with marginalised social movements. CoDesign, vol. 8, no. 2-3, June 2012, pp. 127-144.

Bonacchi, Chiara; Andrew Bevan; Adi Keinan-Schoonbaert; Daniel Pett; and Jennifer Wexler (2019). Participation in heritage crowdsourcing. Museum Management and Curatorship, vol. 34, no. 2, 2019, pp. 166-182.

Borowiecki, Karol Jan; Neil Forbes; and Antonella Fresa, ed. (2016). Cultural Heritage in a Changing World. Cham: Springer International Publishing.

Brewer, Robin; Meredith Ringel Morris; and Anne Marie Piper (2016). "Why would anybody do this?": Older adults' understanding of and experiences with crowd work. In Conference on Human Factors in Computing Systems - Proceedings. New York, NY, USA: Association for Computing Machinery, pp. 2246-2257.

Bujari, Armir; Matteo Ciman; Ombretta Gaggi; and Claudio E. Palazzi (2017). Using gamification to discover cultural heritage locations from geo-tagged photos. Personal and Ubiquitous Computing, vol. 21, no. 2, 2017, pp. 235-252.

Cameron, Fiona; and Sarah Kenderdine (2007). Theorizing Digital Cultural Heritage. Cambridge, Massachussetts: MIT Press.

Crampton, Jeremy W.; Mark Graham; Ate Poorthuis; Taylor Shelton; Monica Stephens; Matthew W. Wilson; and Matthew Zook (2013). Beyond the geotag: situating 'big data' and leveraging the potential of the geoweb. Cartography and Geographic Information Science, vol. 40, no. 2, 2013, pp. 130-139.

Dahlberg-Grundberg, Michael (2016). Technology as movement: On hybrid organizational types and the mutual constitution of movement identity and technological infrastructure in digital activism. Convergence, vol. 22, no. 5, 2016, pp. 524-542.

Dantec, Christopher A. Le; and Carl DiSalvo (2013). Infrastructuring and the formation of publics in participatory design. Social Studies of Science, vol. 43, no. 2, February 2013, pp. 241-264.

Darvish, Sara; and Alvin Chin (2010). Dealing with the video tidal wave: The relevance of expertise for video tagging. In HT '10: Proceedings of the 21st ACM conference on Hypertext and hypermedia, Toronto Ontario, Canada, 13-16 June 12010. New York: ACM, pp. 289-290.

De León, Mireia Alcalá Ponce (2015). Crowdsourcing in the memory institutions: Mass transcriptions. BiD: textos universitaris de biblioteconomia i documentació, vol. 35, no. December, 2015, pp. $1-22$.

Dobreva, Milena (2016). Collective knowledge and creativity: The future of citizen science in the humanities. In S. Kunifuji, G. A. Papadopoulos, A. M. SkulimowskiJ, and J. Kacprzyk (Eds.), Knowledge, Information and Creativity Support Systems. Cham: Springer International Publishing.

Duggan, Maeve; Nicole B. Ellison; Cliff Lampe; Amanda Lenhart; and Mary Madden (2015). Demographics of key social networking platforms. Pew Research Center. http://www.pewinternet.org/2015/01/09/demographics-of-key-social-networking-platforms-2/. Accessed 8 July 2015

Earl, Jennifer; and Katrina Kimpor (2011). Digitally enabled social change : activism in the Internet age. Cambridge: MIT Press. http://libris.kb.se/bib/13510334. Accessed 14 February 2019

Edwards, Richard (2016). Citizen science and lifelong learning. Studies in the Education of Adults, vol. 46, no. 2, 2016, pp. 132-144.

Eveleigh, Alexandra; Charlene Jennett; Stuart Lynn; and Anna L. Cox (2013). "I want to be a captain! I want to be a captain!": gamification in the old weather citizen science project. Proceedings of the First International Conference on Gameful Design, Research, and Applications Gamification '13, 2013, pp. 79-82.

Fort, Karën; Gilles Adda; and K. Bretonnel Cohen (2011). Amazon Mechanical Turk: Gold mine or coal mine? Computational Linguistics, vol. 37, no. 2, 2011, pp. 413-420. 
Gewald, Heiko; and Dennis Pilz (2013). Does money matter? Motivational factors for participation in paid- and non-profit-crowdsourcing communities. Wirtschaftsinformatik Proceedings 2013, vol. Wirtschaft, no. 37, 2013, pp. 577-591.

Grau, Oliver, ed. (2017). Museum and Archive on the Move. Berlin, Boston: De Gruyter.

Hansson, Karin; Thomas Ludwig; and Tanja Aitamurto (2018). Capitalizing relationships: Modes of participation in crowdsourcing. Journal Computer Supported Cooperative Work (JCSCW) Special Issue: Crowd Dynamics: Conflicts, Contradictions, and Cooperation Issues in Crowdsourcing, 2018.

Irani, Lilly C.; and M. Six Silberman (2013). Turkopticon: Interrupting worker invisibility in amazon mechanical turk. In CHI '13: CHI Conference on Human Factors in Computing Systems, Paris, France, 27 April -2 May 2013. Paris, France: ACM, pp. 611-620.

Jones, M. Gail; Gina Childers; Thomas Andre; Elysa N. Corin; and Rebecca Hite (2018). Citizen scientists and non-citizen scientist hobbyists: motivation, benefits, and influences. International Journal of Science Education, Part B: Communication and Public Engagement, vol. 8, no. 4, 2018, pp. 287-306.

Karasti, Helena; Volkmar Pipek; and Geoffrey C. Bowker (2018). An afterword to 'Infrastructuring and collaborative design.' Computer Supported Cooperative Work (CSCW), vol. 27, no. 2, April 2018, pp. 267-289.

Kaufmann, Nicolas; Daniel Veit and Thimo Schulze (2011). More than fun and money. Worker Motivation in crowdsourcing. - A Study on Mechanical Turk. In AMCIS 2011: Proceedings of the Seventeenth Americas Conference on Information Systems, Detroit, Michigan, 4-7 August 2011. pp. 1-11.

Liliana, Melgar Estrada; Michiel Hildebrand; Victor de Boer; and Jacco van Ossenbruggen (2017). Time-based tags for fiction movies: comparing experts to novices using a video labeling game. Communications in Information Literacy, vol. 3, no. 2, 2017, pp. 80-90.

Manzo, Christina; Geoff Kaufman; Sukdith Punjasthitkul; and Mary Flanagan (2015). "By the People, For the People": Assessing the Value of Crowdsourced, User Generated Metadata. Digital Humanities Quarterly, vol. 9, no. 1, 2015, pp. 1-21.

Martin, David; Jacki O’Neill; Neha Gupta; and Benjamin V. Hanrahan (2016). Turking in a global labour market. Computer Supported Cooperative Work (CSCW), vol. 25, no. 1, February 2016, pp. 39-77.

Marx, Karl (1844). Comments on James Mill. http://www.marxists.org/archive/marx/works/1844/ james-mill/. Accessed 24 December 2012

Menking, Amanda; and Ingrid Erickson (2015). The Heart Work of Wikipedia. In CHI '15: Proceedings of the 33rd Annual ACM Conference on Human Factors in Computing Systems, Seoul, Republic of Korea, 18 -23 April 2015. New York: ACM, pp. 207-210.

Oomen, Johan; and Lora Aroyo (2011). Crowdsourcing in the cultural heritage domain: Opportunities and challenges. In $C \& T^{\prime}$ '11: Proceedings of the 5th International Conference on Communities and Technologies, Brisbane, Australia, 29 June 2011 - 2 July, 2011. New York: ACM, pp. 138-149.

Oosterman, Jasper; Jie Yang; Alessandro Bozzon; Lora Aroyo; and Geert Jan Houben (2015). On the impact of knowledge extraction and aggregation on crowdsourced annotation of visual artworks. Computer Networks, vol. 90, 2015, pp. 133-149.

Ortega, Felipe; Jesus M. Gonzalez-Barahona; and Gregorio Robles (2008). On the inequality of contributions to Wikipedia. In HICSS 2008: Proceedings of the 41st Annual Hawaii International Conference on System Sciences, Waikoloa, Big Island, Hawaii, 7-10 January 2008. New York: IEEE, pp. 304-304.

Parcak, Sarah H. (2017). GIS, Remote Sensing, and Landscape Archaeology. Oxford University Press. 
Raddick, M. Jordan; Georgia Bracey; Pamela L. Gay; Chris J. Lintott; Phil Murray; Kevin Schawinski; et al. (2010). Galaxy Zoo: Exploring the motivations of citizen science volunteers. Astronomy Education Review, vol. 9, no. 1, September 2010, pp. 1-15.

Reed, Jason; M. Jordan Raddick; Andrea Lardner; and Karen Carney (2013). An exploratory factor analysis of motivations for participating in Zooniverse, a collection of virtual citizen science projects. Proceedings of the Annual Hawaii International Conference on System Sciences, 2013, pp. 610-619.

Ridge, Mia (2013). From tagging to theorizing: Deepening engagement with cultural heritage through crowdsourcing. Curator: The Museum Journal, vol. 56, no. 4, October 2013, pp. 435-450.

Ridge, Mia (2014). Crowdsourcing our cultural heritage. New York and London: Routledge.

Rorissa, Abebe. (2010). A comparative study of Flickr tags and index terms in a general image collection. Journal of the American Society for Information Science and Technology, vol. 61, no. 11, November 2010, pp. 2230-2242.

Rotman, Dana; Jenny Preece; Jen Hammock; Kezee Procita; Derek Hansen; Cynthia Parr; et al. (2012). Dynamic changes in motivation in collaborative citizen-science projects. Proceedings of the ACM Conference on Computer Supported Cooperative Work, CSCW, 2012, pp. 217-226.

Saldaña, Johnny (2009). The coding manual for qualitative researchers. London: Sage.

Scholz, Trebor (2013). Digital labor: the Internet as playground and factory. (T. Scholz, Ed.). New York: Routledge.

Seaborn, Katie; and Deborah I. Fels (2015). Gamification in theory and action: A survey. International Journal of Human Computer Studies, vol. 74, July 2015, pp. 14-31.

Shelton, Taylor; A. Poorthuis; M. Graham and M. Zook (2014). Mapping the data shadows of hurricane Sandy: Uncovering the sociospatial dimensions of 'Big Data .' Geoforum, vol. 52, no. 2014, 2014, pp. 167-179.

Springer, Michelle; Beth Dulabahn; Phil Michel; Barbara Natanson; David Reser; David Woodward; and Helena Zinkham (2008). For the Common Good: The Library of Congress Flickr Pilot Project.

Terras, Melissa (2011). The digital wunderkammer: Flickr as a platform for amateur cultural and heritage content. Library Trends, vol. 59, no. 4, 2011, pp. 686-706.

van Hooland, Seth; Eva Méndez Rodríguez; and Isabelle Boydens (2011). Between commodification and engagement: On the double-edged impact of user-generated metadata within the cultural heritage sector. Library Trends, vol. 59, no. 4, 2011, pp. 707-720.

Webster, Juliet; and Randle Keith (2016). Virtual workers and the global labour market. (J. Webster and R. Keith, Eds.). Palgrave MacMillan.

Zook, Matthew; Mark Graham; and Andrew Boulton (2015). Crowd-sourced augmented realities: Social media and the power of digital representation. In S. P. Mains, J. Cupples, and C. Lukinbeal (Eds.), Mediated Geographies and Geographies of Media. Dordrecht: Springer Netherlands.

Publisher's Note Springer Nature remains neutral with regard to jurisdictional claims in published maps and institutional affiliations. 